\title{
DESIGNING WITH EMOTIONAL AWARENESS
}

\author{
F. Bianconi ${ }^{1}$, M. Filippucci ${ }^{2}$, G. Magrini ${ }^{3}$, M. Seccaroni ${ }^{4 *}$
}

\begin{abstract}
${ }^{1}$ Department of Civil and Environmental Engineering, 06125 Perugia, Italy - fabio.bianconi@unipg.it ${ }^{2}$ Department of Civil and Environmental Engineering, 06125 Perugia, Italy - marco.filippucci@ unipg.it

${ }^{3}$ Department of Civil and Environmental Engineering, 06125 Perugia, Italy - magrini_giulia@ libero.it

${ }^{4}$ Department of Civil and Environmental Engineering, 06125 Perugia, Italy - marco.seccaroni@ unipg.it
\end{abstract}

KEY WORDS: Perceptual strategies, Emotional responses, VR, Environmental psychology, Neuroscience, Neuroarchitecture, Cultural heritage, Participation.

\begin{abstract}
:
The Italian school building heritage built between the seventies and eighties is every year increasingly abandoned and it remains in a state of neglect. It is increasingly necessary a recovery and enhancement methodology that preserves the memory of the place and at the same time, it makes it capable of adapting to the new needs of the city. The proposed research project originates from the study of the interactions between man and the environment applied to an architectural context with the identification of emotions. This methodology applied to citizenship, aims to make the population participate in the improvement from the point of view of wellbeing. This process was possible thanks to the combined use of immersive reality (VR) and the use of the GEW model, the data of which are the foundation and verification of the choices of architectural design, analyzed through the impacts on humans.
\end{abstract}

\section{INTRODUCTION}

This research focuses on the relationship between school architecture and well-being, focusing on that portion of heritage built from the 1970s to the first half of the 1980s, which represents $40 \%$ of the current class of architectures ${ }^{1}$. In addition to being a fundamental part of the memory of citizens (Lévy, 2002; Maffei, 2007) and the image of the city (Filippucci, 2012; Lynch, 1962; Norberg-Schulz, 2000), it is a class of places that rises a symbolic value for the city (Rossi, 1966), but which absolutely has a profound impact on the life of those who form their conception of space here (Purini, 2021). The buildings must in fact be understood as monuments, essential elements within the urban form, "permanence" (Poëte, 1929) and "signifying signs" (Jencks, 1969), as it tells the etymology of the word linked to the Latin "monere", "to remember", thus also operationally related to childhood.

This issue is transversal to the studies on "Innovative Learning Environments" (Brown and Campione, 1996; Charteris et al., 2017, n.d.; French et al., 2020; Istance and Kools, 2013; Jamieson et al., 2005; Lai and Huang, 2020; Page et al., 2021), which are mainly linked to recovery, because the permanence in time of a building such as a school generates a sense of stability in the common memory, while the opposite would generate abandonment and a wound in the memory (Mugnai, 2016).

Given this need, however, it is necessary to deal with a not indifferent social transformation, linked to a continuous decrease in the birth rate and therefore in the number of students, which, as the annual report of the Italian Ministry shows, in the last 5 years has decreased by $5 \%$. The consequential and progressive abandonment of these spaces, to which are added plans for the new construction of school buildings, opens up an interesting scenario, only partially investigated, on the functional transformation of these buildings.

\footnotetext{
1 Data were processed from the dataset provided by: https://dati.istruzione.it/opendata/opendata/catalogo/elements1/leaf/? datasetId=DS0230EDIETAORIGINESTA

* Corresponding author
}

The starting hypothesis is therefore to rethink a recovery of such spaces without forgetting the deep relationships that these places have in both personal (Ceppi and Zini, 1998) and community (Adler and Goggin, 2005; Francis et al., 2012) identities, respecting an implicit function in the image (Bechtel and Churchman, 2002; Canter, 1977; Gibson, 2018) in their role as common goods (Harvey, 2011; Ostrom, 2015).

In fact, it is assumed that the environment, natural or built, enters into a relationship and influences the actions of those who experience it, as well as their corporeality, their sensations, their psyche (Goldhagen, 2017). Thus opens the theme of "neuroarchitecture" (Ferlaino, 2019; Luis Higuera-Trujillo et al., 2021; Ritchie, 2021), a neologism that shows the interpenetration between architectural themes and studies focused on the impact detected by the nervous system (Chatterjee and Vartanian, 2014; Goldstein, 2007; Lahmiri, 2018; Li et al., 2016; Luis Higuera-Trujillo et al., 2021; Shin et al., 2015; Sloan, 2015; Snowden et al., 2012; Yadava et al., 2017).

Research in the perceptual field has an empirical and substantially subjective character, for which a significant statistical sample of subjects is canonically necessary, but it is an approach also linked to the search for innovative co-design processes (Andersen et al., 2015; Bianconi and Filippucci, 2017; Bratteteig and Wagner, 2012; de Couvreur and Goossens, 2011; Dykes et al., 2009; Lee, 2008; Manzini and Rizzo, 2011; Smith et al., 2017; Trischler et al., 2018), also based on value of serius games (Fabio Bianconi et al., 2020; Checa et al., n.d.; Checa and Bustillo, 2020; Hallinger et al., n.d.; Larson, 2020; Smith et al., 2020; Tomalá-Gonzáles et al., n.d.). The study carried out therefore has the objective of promoting the participation in the design processes of a group of subjects involved in empirical analyzes. At the foundation of the path is the search to understand the perceptual mechanisms and the effects of the different design strategies, going to research "how" the architectural choices play an active role in the mind and body, responding to the psychophysical needs of those who live them, with the aim of improving the impact on their health (Dosen and Ostwald, 2016).

The brain analyzes the environment through our senses and generates behaviors in response to environmental stimuli. One 
of the most efficient ways to examine the impact of the environment on humans is to detect neuronal stimuli by seeking the correlation with perceived external information. Sensory experiences physically change the brain structure, every new information, every new experience, causes a transformation inside the brain in a nanoscopic way. Synaptic plasticity can strengthen or weaken the neurons that the synapses connect, a principle summarized in the phrase "Neuron that fire together, wire together" (Löwel and Singer, 1992), which states that two neurons that often communicate with each other, that is that fire, strengthen their bond. Our way of perceiving is partly conscious but mainly unconscious (unconscious cognition) and perception is intersensory; in the exploration of the environment many senses are therefore involved at the same time, both the more known and intuitive ones (sight, touch, etc.) and the less familiar ones such as interception, thermoception, propioception and the so-called "haptic impressions" (Gallagher, 2006), or tactile impressions; the latter are constituted by the phenomenon that sees the sensorimotor and tactile system activating even just at the sight of something, for example at the sight of a metal handrail the sensorimotor system is already activated by imagining the sensations that would be felt in actually touching the smooth and cold surface of the handrail. However, the fact remains that man can be considered a predominantly visual animal, because more than $50 \%$ of the neurons in his brain respond to this sensory input (Maffei, 2007).

Some neuroscientific studies analyzed have attempted to describe some of the mechanisms that show how differences in various architectural features, cause specific behavioral outcomes (Vartanian et al., 2013), analyzing the multiform behavioral outcomes in comparison with different architectural environments (Choo et al., 2017), or operationally investigating the concept of embodiment (Vecchiato et al., 2015a), by comparing the various contours of architectural forms (Chatterjee and Vartanian, 2014), the height or closure of spaces (Vartanian et al., 2015), the perceptual differences between the built environment and the natural environment (Banaei et al., 2015; Roe et al., 2013) by studying the responses to lighting conditions (Shin et al., 2015), to color (Küller et al., 2009) and the impact of the built environment on human memory.

For these reasons, orientation, light and color, shapes, affordances, sounds and smells are taken as essential elements that condition the environmental experience.

Orienting oneself in space at any scale from architectural to urban is fundamental (Lynch, 1962) and therefore it is necessary to create easily recognizable patterns that are not at right angles but are hexagonal grids (Joncas, 1993) and one's position is defined by referring it to that of two other objects in space so as to form with them an equilateral triangle included in a gray hexagonal. For any given point, the neighboring areas will be located in sixty-degree increments.

The modulation of the intensity of lighting and color can be used as strategies to improve the psychophysiological wellbeing of individuals within the environment, in the form of healthy lighting (Tomassoni et al., 2015). Hence the importance of Light Design and Light Art, and of an ecological and psychological approach to lighting in the living environment (Simon and Toups, 2014). One of the fundamental and more complicated aspects is that of understanding the effects that shapes have on human behavior and perception. We can mean pure, geometric forms with symbols related to culture and anthropology (Banaei et al., 2017). Likewise, one can try to understand from an architectural point of view which are the elements of the built environment that affect perception, such as the geometry of the space and its physical characteristics, to mark architectural elements (Bower et al., 2019) that have a greater impact (scales or ramps; high ceilings; presence of furniture; curvilinear geometries; shapes that make the space legible).

Other materials are also capable of impacting our brain thanks to their texture by stimulating Hapticity, the haptic perception, that is, the ability to induce neurological reactions related to touch (Bower et al., 2019).

An easy reading of the place also passes through the affordances, understood as the set of "possibilities for action" (feasibility) that the organism is able to analyze, in a given environment, through a sophisticated exploration mechanism (Gibson, 1979).

It has been widely demonstrated that sound influences our emotions (Levitin, 2008), as it can be seen in the passage from the inside to the outside of a cathedral, from the noise of the square to the silence of the place of worship (Kang and SchulteFortkamp, 2017; Lawrence, 2003; Schafer, 1994).

The sense of smell has a unique correlation with emotion, with its intertwined olfactory neuroanatomy, through extensive reciprocal axonal connections, with primary emotional areas including the amygdala, hippocampus and orbitofrontal cortex (Haberly, 2001).

In 1980 Russel and Pratt (Russell, 1980) proposed a model for motivating the relationship between environmental factors and people's behavior. Their research confirmed, in fact, that pleasure and arousal are two independent dimensions in all situations. This model consists of a two-dimensional scheme that identifies two related dimensions, resulting from each interaction of the two basic ones (pleasure and activation), obtaining eight descriptors of emotional reactions to the environment: pleasure (pleasure); activation (arousal); excitement; happiness; joy; sadness; fatigue; relaxation.

The Geneva Emotion Wheel (Sacharin, V., Schlegel, K., \& Scherer, 2012; Scherer, 2005) also derives from this type of model. This tool is used to measure as precisely as possible the emotion felt by the subjects of an experiment to make it easier to report the type of emotion experienced. Twenty different emotions are arranged in a circular manner on the answer sheet. These are actually words that represent "families of emotions" and can therefore refer to a whole series of similar emotions: for example, the "anger" family also covers emotions such as anger, ire, harassment, annoyance, indignation, exasperation or irritation; the family of "fear" includes anxiety, worry, apprehension or panic.

These issues appear today extremely coherent with the architectural tendency inherent in biophilic design (Kellert et al., n.d.; Wilson, 1984), and that attention to natural aspects that enhances sensations, declining a relationship between architecture and emotions that is at the center of the aesthetic research, but which today is increasingly becoming a result of scientific analysis.

The aim of the experimentation is to introduce the use of virtual reality for spatial emotional analysis in relation to architecture, interior design, environmental psychology, neuroarchitecture and spatial analysis. The models created are projected towards the likelihood with reality (Ward, 1994), to find a greater correspondence of the perceptual outputs, however analyzed in an artificial environment (Gračanin, 2018), having already determined the sensory correspondences between reality and simulation (Balakrishnan et al., 2006; Bianconi et al., 2019, 2018; F. Bianconi et al., 2020; Glicksohn et al., 2017; Kroupi et al., 2014; Scholz and Smith, 2016; Slater and Sanchez-Vives, 2016; Vecchiato et al., 2015b).

\section{EXPERIMENTATION}

The experimental work was modulated in various phases: first of all the psychological, neurological and sensorial responses to 
the inputs coming from the environment in which the human being lives for the majority of his time, i.e. inside of the built environment; subsequently it was necessary to identify some of the variables, the elements that influence perceptions and emotional responses in the surrounding built environment; finally determine, as these elements vary, how the emotional responses to places vary.

Cognitive experimentation, with a view to a co-design of architectural spaces, is projected to create a procedure to highlight the emotional and sensational relationship in the use of the interior of a building. For these reasons, the solutions adopted for the interior design through certain characteristics and specific configurations are aimed at achieving specific emotions related to the functions of each space.
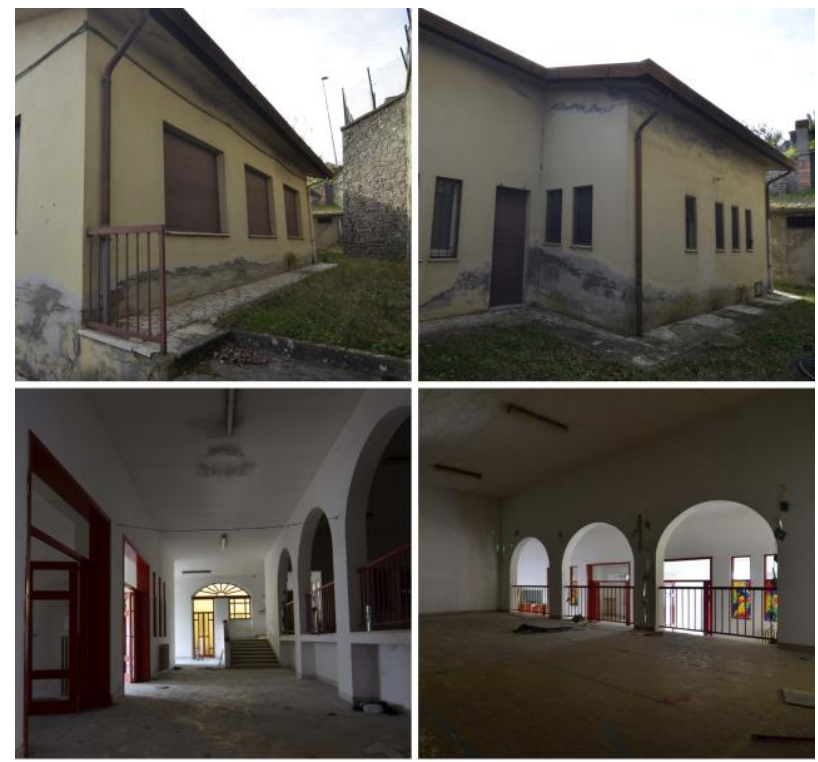

Figure 1. Current status of the Municipal Nursery School of Anghiari.

The building that housed the headquarters of the Municipal Nursery School of Anghiari in the province of Arezzo was chosen as a case study. The building was completed in 1976 and designed by the architect Giorgio Alessandro Giannini, assisted by the engineer Guido Peruzzi. This architectural space represents a classic example of the school structures built in the central period for this building class, a space that is now abandoned in the face of new solutions to meet training needs. Following an analysis of the urban context and a comparison with local authorities, the transformation of the space into a cultural center was hypothesized. Central is the theme of memory, which enters the subconscious of an important portion of the community that has lived in these spaces, a reason that reinforces the value of the hypothesized destination. Therefore, given the hypothesis of keeping elements of reference to the image settled in the memory, it was decided to keep the external appearance of the asset and some characteristics of the internal configuration precisely to support the recognition processes.

The route includes entry into four environments (rooms), with specific functions, aimed at enhancing certain emotions:

1) The first room is dedicated to art exhibitions and artistic workshops. The goal of the project is to stimulate creativity, to involve the user by increasing his sense of attention, stimulation and satisfaction. These feelings are generated when admiring works of art and when producing thoughts related to the creation of new ideas, especially through drawing. The colors used for the walls are purple that stimulates creativity and blue, both with a medium-high saturation and high brightness. There are works of art whose observation causes the activation of certain areas of the brain related to the admiration of beauty.

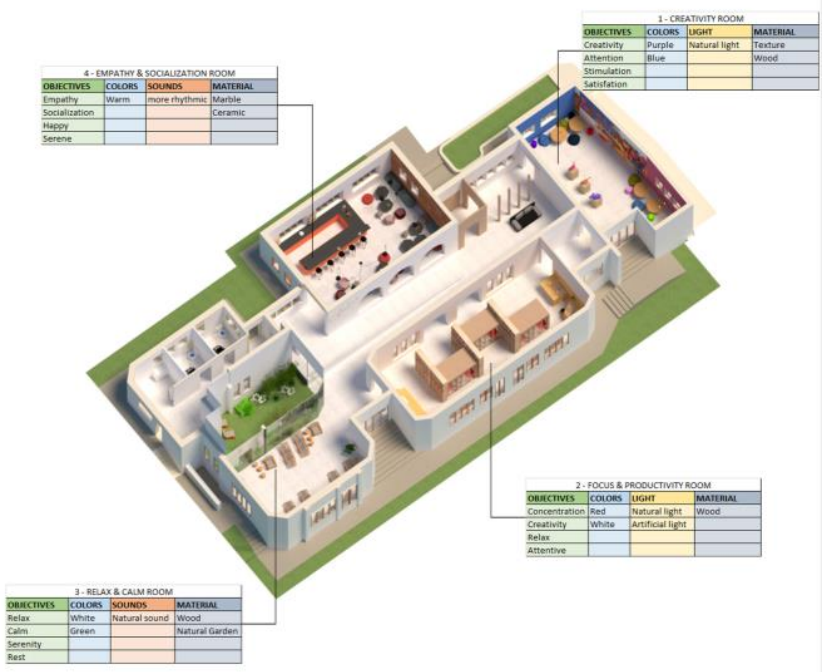

Figure 2 Project outline: objectives, colours, sounds, lights and materials used.

The works used are by the Italian-Filipino illustrator and street artist Philip Giordano. These, constituting colored textures, stimulate sight by increasing the saccades, increasing the stimuli necessary for creative activity. In particular, the works included are entitled "Carboniferous", "Ueno" and "Playtime winter season". The presence of numerous openings on the three external sides of the room, the largest facing south-east, guarantees the entry of a lot of natural light. Furthermore, the furnishings chosen, with their soft shapes and freely modifiable arrangement, create a fluid and flexible environment, facilitating the three emotions mentioned. The furnishings also stimulate the haptic perception as they have irregular softness and texture. The tables, the supports of the works are made of wood, this to encourage pleasant sensations of warmth and keep the levels of attention high.

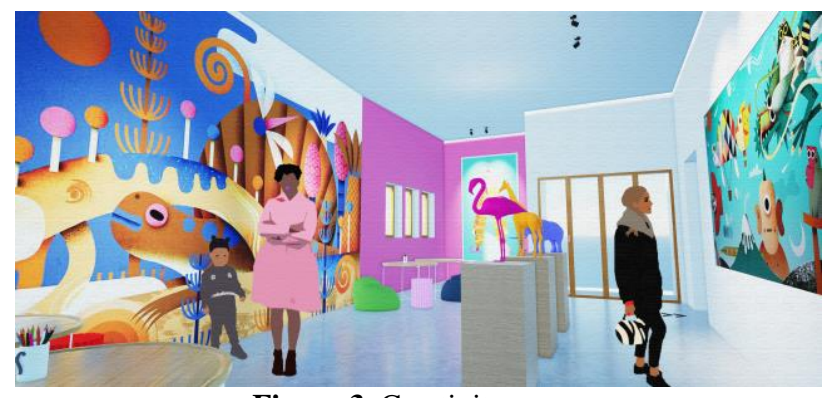

Figure 3. Creativity room.

2) The second room is a small library with areas for studying and reading. The environment is designed to enhance concentration and creativity, so that the user feels satisfied, relaxed and attentive. In fact, in order to carry out a task such as studying or reading, excessive stress factors must be avoided, this is why the term fulfilled delineates the aspect of satisfaction combined with calm. The glazed surface covers about forty-five percent of the side wall facing south-east. The opposite wall has large openings on the central corridor, a study in fact demonstrates the decrease of satisfaction in the subjects who study looking towards a wall and the increase in attention and concentration levels in students who are able to see the entrances of the room where a task has to be carried out. In 
addition, boxes have been inserted where the artificial zenith lighting provided favors concentration. However, the boxes have sliding glass doors for the reasons mentioned above. There are both open and flexible study/reading areas, with the use of movable seats and stools, and fixed workstations. In fact, studies show that students prefer chairs but use stools as a support for personal items. All sessions feature soft materials as they have been shown to cause increased concentration and satisfaction. Small red spots increase visual engagement, promoting productivity. The material that clearly appears predominantly is wood, given its ability to increase productivity. As for the auditory stimulation, a low sound with alpha waves was chosen in order to reduce anxiety states and increase satisfaction, on the other hand, in fact, sounds with greater meaning (such as songs with words) were less capable to reduce anxiety and increase satisfaction.

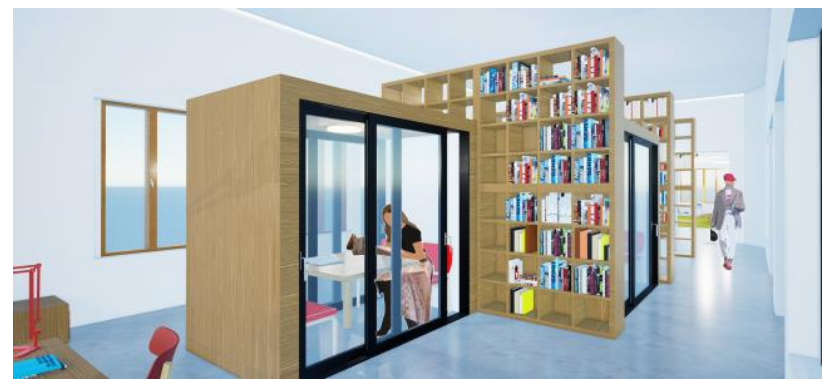

Figure 4. Focus \& productivity room.

3) The third room is a relaxation area, therefore linked to creating feelings of calm, serenity and rest. We opted for a glass surface on each side, moreover, the room is located in correspondence with the courtyard allowing direct contact with the garden. Green is present both in the courtyard and in the indoor plants and, in addition, the interior carpets are also green in order to recreate the effect of a lawn in continuity with that in the courtyard. As for the seats, affordances in this case, for relaxation, the Model 31 and 39 by Alvar Aalto were chosen. With the exception of the green, the other colors in the room have bright tones and little contrast. The other furnishing elements, mainly curved in shape, are also designed for a better aesthetically perceived rendering and to refer to the concept of softness both in the shapes and in the materials, in order to induce calm and serenity. As for the sounds, it was decided to reproduce sounds recorded in the middle of nature.

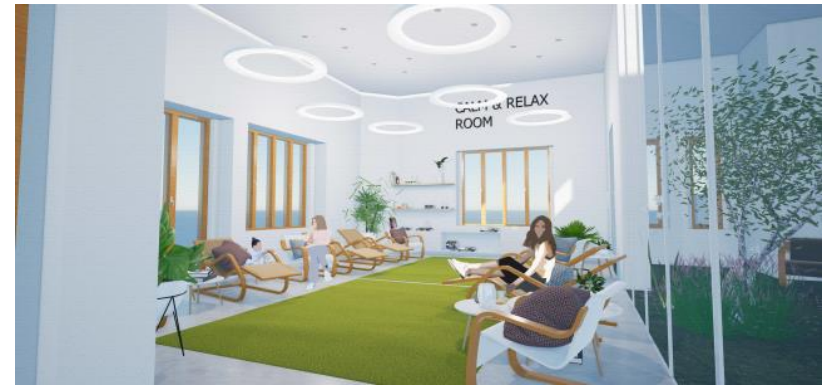

Figure 5. Relax \& calm room.

4) The last space is a refreshment area with a coffee.

The goal is to enhance empathy and socialization, associating food and sociability, to bring the user to feel happy, stimulated and serene. The colors used are mainly warm and vibrant but there is also the contrast with cold colors. The materials are also marble and, as regards the finish of the north wall, ceramic with a rough and three-dimensional appearance, in order to induce the involvement of haptic perception through sight and, through contrasts, greater emotional stimulation. The hexagonal shape of the tables takes up the strategy of arranging objects and furnishings in a grid with a hexagonal mesh in order to improve the ability to orient oneself in space and to understand it. The sounds chosen are more rhythmic, in order to increase the heartbeat slightly and there is the reproduction of sounds such as the banging of cutlery, the clink of glasses and plates, and there are also voices in the background that are not legible in order to bring back to the memory moments in which one actually found oneself within a similar space, inducing the activation of mechanisms related to memory.

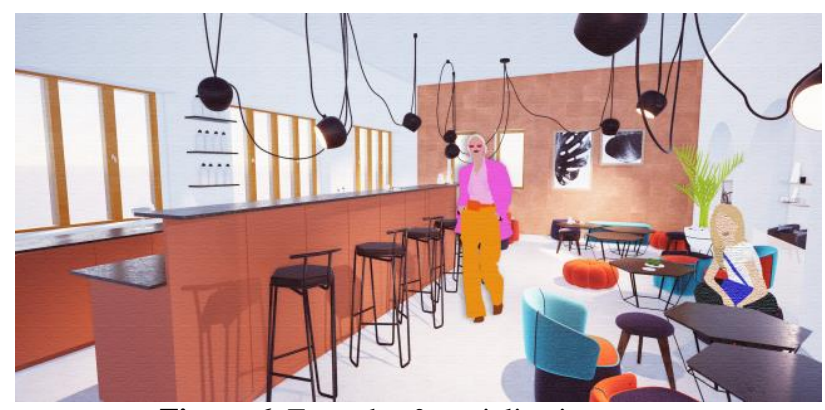

Figure 6. Empathy \& socialization room.

The use of the space therefore also provides the possibility of an emotional journey, in the variation from one emotion to another along an itinerary, even if the user can choose to visit the structure freely and use each space for specific needs or wishes. The fluidity between the spaces is achieved through the use of large and rhythmic openings. The main corridor is for the same reasons designed to generate chiaroscuro contrasts and symmetries, in order to guarantee a stimulus to the visitor's curiosity at the beginning of the path.

Also, in the main atrium there is a ramp that opens up the space. The building is designed to be clearly legible in its entirety, finding in this space references of the external space that help orientation, with the view of the courtyard/garden and the panorama dominated by the building. This condition favors the stimulation of the sensorimotor system and the clarity of the figurative structure guarantees that security that generates a feeling of calm but at the same time stimulates the exploration of space.

In addition to visual enhancement, auditory stimuli are also included. Each environment is flooded with sounds which, according to the studies reported above, predispose the individual to achieving a certain emotional mindset.

These elements characterize the built immersive space, where participants can navigate independently, by choosing where to turn their gaze and the ways and times of exploration of the same. The request addressed to the premise of the empirical experience detected is to explore the project on screen and to respond to a questionnaire that, on the GWE model, could report the emotions felt within each room as reliably as possible. In addition, questions were also raised on the activities that could be carried out within the spaces designed in order to highlight what the action settings and affordances were perceived in a predominant way.

Immersive reality was first modeled via SketchUp and then imported into Unreal Engine to make it interactive and navigable. Google Forms was used for the construction of the questionnaire and the collection of data.

The virtual visit and the compilation of the self-reports were carried out remotely by the participants individually. Data was collected from 40 participants aged 35 to 55 who attended the school in question. Through the questionnaire, everyone voted a 
scale of intensity from zero to six of perception of a determined series of emotions, in each room virtually visited.

The data was collected in a spreadsheet, the averages of each emotion on each room were calculated, and the complex diagrams were then constructed.

The diagram is divided into four quadrants corresponding to the emotions sought in the four environments.

\section{RESULTS}

From the data acquired and represented through the Kiviat diagram (fig.7) it emerges that for the Creativity Room the testers are for the most part stimulated, attentive and pleased. As for the Focus \& Productivity Room, on average, they feel attentive, satisfied and relaxed.

The Relax \& Calm Room testers feel calm, relaxed and serene. In the Empathy \& Socialization Room they felt stimulated, happy and serene.
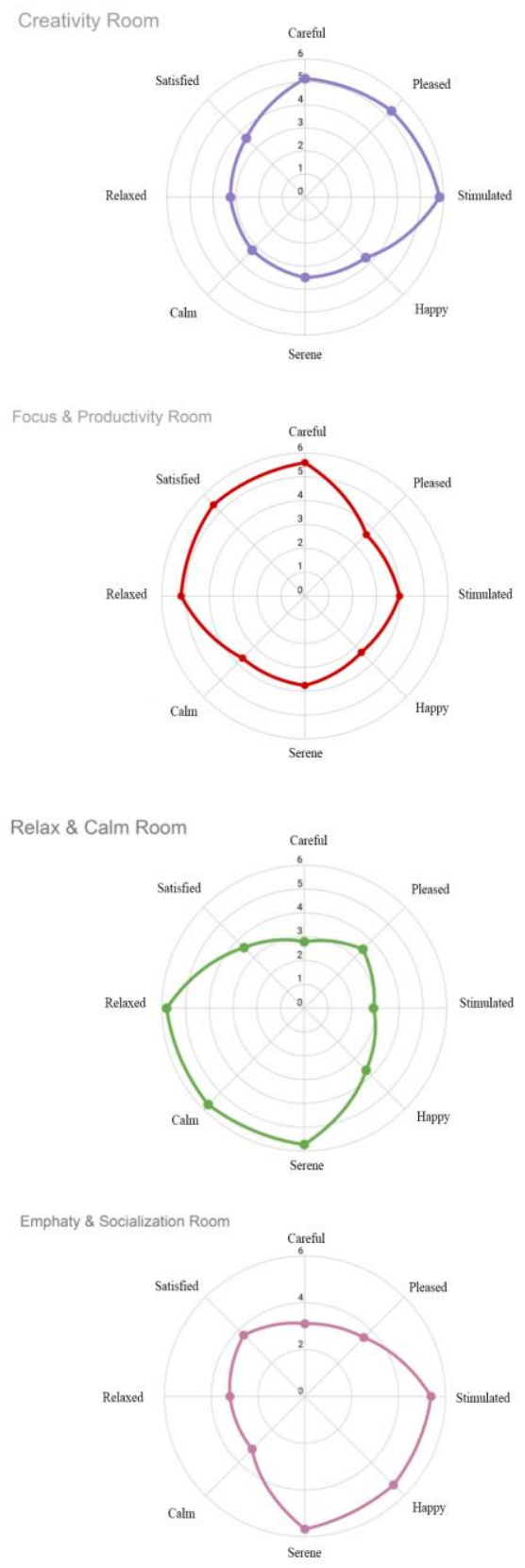

Figure 7. Kyviat diagram in the respective room.

\section{CONCLUSION}

The participatory approach through virtual reality has made it possible to identify how, by modifying the architectural space, it is possible to change its best use. The study of the variability of space has revealed ranges of solutions and their impact despite being analyzed in certain combinations. The co-design of users in the choice of functions is correlated to a process aimed at awareness, which provides the subject, conceived as the client, the correspondence of significant patterns, equally proposing quantitative and qualitative indications for the designer called to think of these environments as a function of "service" that they create for the well-being of the people who live in there.

\section{REFERENCES}

Adler, R.P., Goggin, J., 2005. What Do We Mean By "Civic Engagement"? J. Transform. Educ. 3, 236-253. https://doi.org/10.1177/1541344605276792

Andersen, L.B., Danholt, P., Halskov, K., Hansen, N.B., Lauritsen, P., 2015. Participation as a matter of concern in participatory design. CoDesign. https://doi.org/10.1080/15710882.2015.1081246

Balakrishnan, B., Kalisperis, L.N., Sundar, S.S., Effects, M., 2006. Capturing Affect in Architectural Visualization.

Banaei, M., Hatami, J., Yazdanfar, A., Gramann, K., 2017. Walking through Architectural Spaces: The Impact of Interior Forms on Human Brain Dynamics. Front. Hum. Neurosci. 11. https://doi.org/10.3389/fnhum.2017.00477

Banaei, M., Yazdanfar, A., Nooreddin, M., Yoonessi, A., 2015. Enhancing Urban Trails Design Quality by Using Electroencephalography Device. Procedia - Soc. Behav. Sci. 201, 386-396. https://doi.org/10.1016/j.sbspro.2015.08.191

Bechtel, R.B., Churchman, A., 2002. Handbook of environmental psychology. J. Wiley \& Sons, New York.

Bianconi, F., Filippucci, M., 2017. Codesign, Social Contracts, Environmental Citizenship. The Case Study of Umbrian Region's Atlas of Objectives and Lake Trasimeno Landscape Contract, in: Putting Tradition into Practice: Heritage, Place and Design. Proceedings of 5th INTBAU International Annual Event. Springer, pp. 1432-1441.

Bianconi, F., Filippucci, M., Angelini, G.M., 2018. Immersive BIM: l'approccio integrato BIM to VR nelle ipotesi progettuali per il campus di Pentima., in: 3D MODELING \& BIM. Nuove Frontiere. DEI s.r.l. TIPOGRAFIA DEL GENIO CIVILE, Roma, pp. 96-107.

Bianconi, Fabio, Filippucci, M., Cornacchini, F., 2020. PLAY AND TRANSFORM THE CITY. sciresit.it 2, 141-158. https://doi.org/10.2423/i22394303v10n2p141

Bianconi, F., Filippucci, M., Cornacchini, F., 2020. Play and Transform the City. SCIRES-IT 10 https://doi.org/10.2423/i22394303v10n2p141 
Bianconi, F., Filippucci, M., Felicini, N., 2019. Immersive Wayfinding: virtual reconstruction and eye-tracking for orientation studies inside complex architecture., in: INTERNATIONAL ARCHIVES OF THE PHOTOGRAMMETRY, REMOTE SENSING AND SPATIAL INFORMATION SCIENCES. Elsevier, pp. 143-150. https://doi.org/10.5194/isprs-archives-XLII-2-W9-143-2019

Bower, I., Tucker, R., Enticott, P.G., 2019. Impact of built environment design on emotion measured via neurophysiological correlates and subjective indicators: A systematic review. J. Environ. Psychol. 66, 101344. https://doi.org/10.1016/j.jenvp.2019.101344

Bratteteig, T., Wagner, I., 2012. Spaces for participatory

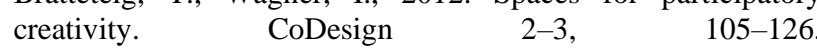
https://doi.org/10.1080/15710882.2012.672576

Brown, A., Campione, J., 1996. Psychological theory and the design of innovative learning environments: On procedures, principles, and systems.

Canter, D. V., 1977. The psychology of place. Architectural Press, New York.

Ceppi, G., Zini, M. (Eds.), 1998. Children, spaces, relations : metaproject for an environment for young children. Reggio Children, Reggio Emilia.

Charteris, J., Smardon, D., Continuing, S.K.-S. in, 2021, undefined, n.d. Leadership in the built spaces of innovative learning environments: leading change in people and practices in the perfectly self-managing society. Taylor Fr.

Charteris, J., Smardon, D., Nelson, E., 2017. Innovative learning environments and new materialism: A conjunctural analysis of pedagogic spaces. Taylor Fr. 37, 808-821. https://doi.org/10.1080/00131857.2017.1298035

Chatterjee, A., Vartanian, O., 2014. Neuroaesthetics. Trends Cogn. Sci. https://doi.org/10.1016/j.tics.2014.03.003

Checa, D., Applications, A.B.-M.T. and, 2020, undefined, n.d. A review of immersive virtual reality serious games to enhance learning and training. Springer.

Checa, D., Bustillo, A., 2020. A review of immersive virtual reality serious games to enhance learning and training. Multimed. Tools Appl. 79, 5501-5527. https://doi.org/10.1007/s11042-019-08348-9

Choo, H., Nasar, J.L., Nikrahei, B., Walther, D.B., 2017. Neural codes of seeing architectural styles. Sci. Rep. 7. https://doi.org/10.1038/srep40201

de Couvreur, L., Goossens, R., 2011. Design for (every)one: Co-creation as a bridge between universal design and rehabilitation engineering. CoDesign 7, 107-121. https://doi.org/10.1080/15710882.2011.609890
Dosen, A.S., Ostwald, M.J., 2016. Evidence for prospect-refuge theory: a meta-analysis of the findings of environmental preference research. City, Territ. Archit. 3, 4. https://doi.org/10.1186/s40410-016-0033-1

Dykes, T.H., Rodgers, P.A., Smyth, M., 2009. Towards a new disciplinary framework for contemporary creative design practice.

https://doi.org/10.1080/15710880902910417

CoDesign.

Ferlaino, M., 2019. Neuroarchitecture: quantifying perception to inform a design for improved mental well-being.

Filippucci, M., 2012. Dalla forma urbana all'immagine della città. Percezione e figurazione all'origine dello spazio costruito. Sapienza Università di Roma.

Francis, J., Giles-Corti, B., Wood, L., Knuiman, M., 2012. Creating sense of community: The role of public space. J. Environ. Psychol. 4, 401-409. https://doi.org/10.1016/j.jenvp.2012.07.002

French, R., Imms, W., Mahat, M., 2020. Case studies on the transition from traditional classrooms to innovative learning environments: Emerging strategies for success. Improv. Sch. 23, 175-189. https://doi.org/10.1177/1365480219894408

Gallagher, S., 2006. How the Body Shapes the Mind, How the Body Shapes the Mind. Oxford University Press. https://doi.org/10.1093/0199271941.001.0001

Gibson, J.J., 2018. The Ecological Approach to Visual Perception. Psychology Press, London. https://doi.org/10.2307/j.ctt1xp3nmm.20

Gibson, J.J., 1979. The Ecological Approach to Visual Perception. Taylor \& Francis, Milton Park.

Glicksohn, J., Berkovich-Ohana, A., Mauro, F., Ben-Soussan, T.D., 2017. Time perception and the experience of time when immersed in an altered sensory environment. Front. Hum. Neurosci. 11. https://doi.org/10.3389/fnhum.2017.00487

Goldhagen, S.W., 2017. Welcome to Your World. How the Built Environment Shapes Our Lives. HarperCollins, New York.

Goldstein, E.B., 2007. Sensation and perception. Thomson/Wadsworth, Belmont.

Gračanin, D., 2018. Immersion versus embodiment: Embodied cognition for immersive analytics in mixed reality environments, in: Lecture Notes in Computer Science (Including Subseries Lecture Notes in Artificial Intelligence and Lecture Notes in Bioinformatics). pp. 355-368. https://doi.org/10.1007/978-3-319-91470-1_29

Haberly, L.B., 2001. Parallel-distributed Processing in Olfactory Cortex: New Insights from Morphological and Physiological Analysis of Neuronal Circuitry. Chem. Senses 26, 


\section{1-576. https://doi.org/10.1093/chemse/26.5.551}

Hallinger, P., Wang, R., ... C.C.-J. of C., 2020, undefined, n.d. A bibliometric review of research on simulations and serious games used in educating for sustainability, 1997-2019. Elsevier.

Harvey, D., 2011. The Future of the Commons. Radic. Hist. Rev. 101-107. https://doi.org/10.1215/01636545-2010-017

Istance, D., Kools, M., 2013. OECD Work on Technology and Education: Innovative learning environments as an integrating framework. Eur. J. Educ. 48, 43-57. https://doi.org/10.1111/ejed.12017

Jamieson, P., Dane, J., Lippman, P.C., 2005. Moving beyond the classroom: Accommodating the changing pedagogy of higher education, in: Proceedings of 2005 Forum of the Australasian Association for Institutional Research. pp. 17-23.

Jencks, C., 1969. Meaning in architecture. The Cresset Press, London.

Joncas, R., 1993. Pedagogy and "Reflex": Frank Lloyd Wright's Hanna House Revisited. J. Soc. Archit. Hist. 52, 307 322. https://doi.org/10.2307/990837

Kang, J., Schulte-Fortkamp, B. (Eds.), 2017. Soundscape and the built environment. CRC Press, Boca Raton.

Kellert, S.R., Heerwagen, J.H., Mador, M.L. (Eds.), n.d. Biophilic Design: The Theory, Science, and Practice of Bringing Buildings to Life. John Wiley \& Sons Inc.

Kroupi, E., Hanhart, P., Lee, J.S., Rerabek, M., Ebrahimi, T., 2014. Predicting subjective sensation of reality during multimedia consumption based on EEG and peripheral physiological signals. Proc. - IEEE Int. Conf. Multimed. Expo 2014-Septe. https://doi.org/10.1109/ICME.2014.6890239

Küller, R., Mikellides, B., Janssens, J., 2009. Color, arousal, and performance - A comparison of three experiments. Color Res. Appl. 34, 141-152. https://doi.org/10.1002/col.20476

Lahmiri, S., 2018. Neuromarketing Perspective of Consumer Choice, in: Applications of Neuroscience. pp. 286-295. https://doi.org/10.4018/978-1-5225-5478-3.ch013

Lai, C., Huang, X., 2020. Teachers' socio-spatial practice in innovative learning environments. Artic. Cambridge J. Educ. 50, 521-538. https://doi.org/10.1080/0305764X.2020.1736003

Larson, K., 2020. Serious Games and Gamification in the Corporate Training Environment: a Literature Review. TechTrends. https://doi.org/10.1007/s11528-019-00446-7

Lawrence, I., 2003. Soundscapes. Phys. Educ. 38, 294-299. https://doi.org/10.1088/0031-9120/38/4/301
Lee, Y., 2008. Design participation tactics: the challenges and new roles for designers in the co-design process. CoDesign 4 , 31-50. https://doi.org/10.1080/15710880701875613

Levitin, D., 2008. This Is Your Brain On Music: Understanding a Human Obsession. Edward Payson Dutton, New York.

Lévy, P., 2002. L’intelligenza collettiva. Per un'antropologia del cyberspazio. Feltrinelli, Milano.

Li, B., Wang, Y., Wang, K., 2016. Data fusion and analysis techniques of neuromarketing. WIT Trans. Eng. Sci. 113, $396-$ 404. https://doi.org/10.2495/IWAMA150461

Löwel, S., Singer, W., 1992. Selection of intrinsic horizontal connections in the visual cortex by correlated neuronal activity. $\begin{array}{lllll}\text { Science } & \text { (80-. 209-212. }\end{array}$ https://doi.org/10.1126/science.1372754

Luis Higuera-Trujillo, J., Llinares, C., Macagno, E., 2021. The Cognitive-Emotional Design and Study of Architectural Space: A Scoping Review of Neuroarchitecture and Its Precursor Approaches. mdpi.com. https://doi.org/10.3390/s21062193

Lynch, K., 1962. The Image of the City, The Journal of Aesthetics and Art Criticism. MIT Press, Massachusetts. https://doi.org/10.2307/427643

Maffei, L., 2007. I diversi sentieri della memoria e l'arte visiva, in: Pinotti, A., Lucignani, G. (Eds.), Immagini Della Mente : Neuroscienze, Arte, Filosofia. Cortina Raffaello, Milano, pp. 69-81.

Manzini, E., Rizzo, F., 2011. Small projects/large changes: Participatory design as an open participated process. CoDesign 7, 199-215. https://doi.org/10.1080/15710882.2011.630472

Mugnai, M., 2016. Ontology and Logic: The Case of Scholastic and Late-Scholastic Theory of Relations. Br. J. Hist. Philos. 24, 532-553. https://doi.org/10.1080/09608788.2016.1154005

Norberg-Schulz, C., 2000. Architecture: presence, language and place, Skira architecture library. Skira, Losanna.

Ostrom, E., 2015. Governing the commons: The evolution of institutions for collective action, Governing the Commons: The Evolution of Institutions for Collective Action. Cambridge University Press. https://doi.org/10.1017/CBO9781316423936

Page, A., Anderson, J., Charteris, J., 2021. Including students with disabilities in innovative learning environments: a model for inclusive practices Special and Inclusive Education Discussions-Public Focus View project Cyber Security and Social Media: Securing students' well-being View project. Artic. Int. J. Incl. https://doi.org/10.1080/13603116.2021.1916105

Poëte, M., 1929. Introduction à l'urbanisme: l'évolution des villes, la leçon de l'Antiquité. Boivin, Paris. 
Purini, F., 2021. Landscapes and the Concepts of Landscape, in: Lecture Notes in Civil Engineering. Springer Science and Business Media Deutschland GmbH, pp. 111-132. https://doi.org/10.1007/978-3-030-59743-6_3

Ritchie, I., 2021. Neuroarchitecture: Designing with the Mind in Mind.

Roe, J.J., Aspinall, P.A., Mavros, P., Coyne, R., 2013. Engaging the brain: the impact of natural versus urban scenes using novel EEG methods in an experimental setting. Environ. Sci. 1, 93104. https://doi.org/10.12988/es.2013.3109

Rossi, A., 1966. L'architettura della città. Marsilio, Padova.

Russell, J.A., 1980. A circumplex model of affect. J. Pers. Soc. Psychol. 39, 1161-1178. https://doi.org/10.1037/h0077714

Sacharin, V., Schlegel, K., \& Scherer, K.R., 2012. GEW Report August 13201213.

Schafer, R.M., 1994. The soundscape: our sonic environment and the tuning of the world. Destiny Books, Merrimac.

Scherer, K.R., 2005. What are emotions? and how can they be measured? Soc. Sci. Inf. 44, 695-729. https://doi.org/10.1177/0539018405058216

Scholz, J., Smith, A.N., 2016. Augmented reality: Designing immersive experiences that maximize consumer engagement. $\begin{array}{llll}\text { Bus. Horiz. } & \text { 59, } & \text { 149-161. }\end{array}$ https://doi.org/10.1016/j.bushor.2015.10.003

Shin, Y. Bin, Woo, S.H., Kim, D.H., Kim, J., Kim, J.J., Park, J.Y., 2015. The effect on emotions and brain activity by the direct/indirect lighting in the residential environment. Neurosci. Lett. 584, 28-32. https://doi.org/10.1016/j.neulet.2014.09.046

Simon, M.A., Toups, L., 2014. Innovation in Deep Space Habitat Interior Design: Lessons Learned from Small Space Design in Terrestrial Architecture, in: AIAA SPACE 2014 Conference and Exposition. American Institute of Aeronautics and Astronautics, Reston, Virginia. https://doi.org/10.2514/6.2014-4474

Slater, M., Sanchez-Vives, M. V, 2016. Enhancing Our Lives with Immersive Virtual Reality. Front. Robot. AI 3. https://doi.org/10.3389/frobt.2016.00074

Sloan, C., 2015. Neuroeconomics and neuromarketing. Int. J. Bus. Manag. Econ. Res. 6, 133-136. Retrieved from http://ijbmer.com.

Smith, J., Sears, N., Taylor, B., Johnson, M., 2020. Serious games for serious crises: Reflections from an infectious disease outbreak matrix game. Global. Health 16. https://doi.org/10.1186/s12992-020-00547-6 design in an era of participation. CoDesign 13, 65-69. https://doi.org/10.1080/15710882.2017.1310466

Snowden, R.J., Thompson, P., Troscianko, T., 2012. Basic vision: an introduction to visual perception. OUP Oxford, Oxford.

Tomalá-Gonzáles, J., ... J.G.-Q.-2020 15th I., 2020, undefined, n.d. Serious games: Review of methodologies and games engines for their development. ieeexplore.iee.org.

Tomassoni, R., Galetta, G., Treglia, E., 2015. Psychology of Light: How Light Influences the Health and Psyche. Psychology 06, 1216-1222. https://doi.org/10.4236/psych.2015.610119

Trischler, J., Pervan, S.J., Kelly, S.J., Scott, D.R., 2018. The Value of Codesign: The Effect of Customer Involvement in Service Design Teams. J. Serv. Res. https://doi.org/10.1177/1094670517714060

Vartanian, O., Navarrete, G., Chatterjee, A., Fich, L.B., Gonzalez-Mora, J.L., Leder, H., Modroño, C., Nadal, M., Rostrup, N., Skov, M., 2015. Architectural design and the brain: Effects of ceiling height and perceived enclosure on beauty judgments and approach-avoidance decisions. J. Environ. Psychol. 41, 10-18. https://doi.org/10.1016/j.jenvp.2014.11.006

Vartanian, O., Navarrete, G., Chatterjee, A., Fich, L.B., Leder, H., Modrono, C., Nadal, M., Rostrup, N., Skov, M., 2013. Impact of contour on aesthetic judgments and approachavoidance decisions in architecture. Proc. Natl. Acad. Sci. U. S A. 110, 10446-10453. https://doi.org/10.1073/pnas.1301227110

Vecchiato, G., Tieri, G., Jelic, A., De Matteis, F., Maglione, A.G., Babiloni, F., 2015a. Electroencephalographic correlates of sensorimotor integration and embodiment during the appreciation of virtual architectural environments. Front. Psychol. 6. https://doi.org/10.3389/fpsyg.2015.01944

Vecchiato, G., Tieri, G., Jelic, A., De Matteis, F., Maglione, A.G., Babiloni, F., 2015b. Electroencephalographic correlates of sensorimotor integration and embodiment during the appreciation of virtual architectural environments. Front. Psychol. 6. https://doi.org/10.3389/fpsyg.2015.01944

Ward, G.J., 1994. The RADIANCE lighting simulation and rendering system, in: Proceedings of the $21 \mathrm{st}$ Annual Conference on Computer Graphics and Interactive Techniques, SIGGRAPH 1994. Association for Computing Machinery, Inc, New York, New York, USA, pp. 459-472. https://doi.org/10.1145/192161.192286

Wilson, E.O., 1984. Biophilia. Harvard University Press.

Yadava, M., Kumar, P., Saini, R., Roy, P.P., Prosad Dogra, D., 2017. Analysis of EEG signals and its application to neuromarketing. Multimed. Tools Appl. 76, 19087-19111. https://doi.org/10.1007/s11042-017-4580-6 